\title{
RELAÇÕES PEDAGÓGICAS ENTRE EDUCAÇÃO FíSICA ESCOLAR E JOGOS OLÍMPICOS
}

\author{
Viviane Ribeiro Paes \\ Universidade Estadual de Campinas, Campinas, São Paulo, Brasil \\ Osmar Moreira de Souza Júnior \\ Universidade Federal de São Carlos, São Carlos, São Paulo, Brasil
}

\begin{abstract}
Resumo
O presente estudo teve o objetivo de investigar e analisar as perspectivas de professores de Educação Física em relação às suas práticas pedagógicas com a realização dos Jogos Olímpicos de 2016 no Brasil. Para a realização deste estudo, utilizou-se a abordagem qualitativa por meio de entrevista semiestruturada com seis professores de Educação Física, atuantes na rede estadual de São Carlos/SP. Foi utilizada a análise categorial de dados e percebeu-se que os docentes elencaram possibilidades de diálogo sobre os Jogos Olímpicos em suas aulas, apesar de apresentarem em alguns momentos uma visão limitada e esportivista. Considera-se importante o debate da tematização crítica dos Jogos Olímpicos na escola, sendo os professores os protagonistas desse processo.
\end{abstract}

Palavras chave: Educação Física Escolar. Jogos Olímpicos. Prática Pedagógica.

\section{Introdução}

Muitos atributos considerados importantes para o desenvolvimento da sociedade brasileira foram, a partir da década de 1960, sendo incorporados ao esporte como um princípio de formação do indivíduo. As regras, o convívio e os sentimentos de disputa, a rivalidade e o companheirismo do esporte somaram-se gradativamente ao habitus dos sentidos atribuídos às aulas de Educação Física, passando então a serem vistos como aprendizagens propostas e almejadas para o desenvolvimento pleno do aluno. Também se ambicionava a expansão do esporte nacional por meio da preparação de futuros atletas brasileiros na escola, que promoveriam o país em meio às nações desenvolvidas ao atingirem destaque no nível internacional (BETTI, 1991).

Dessa forma, surge no Brasil um sistema que visava integralizar os âmbitos esportivos e divisá-los em níveis hierárquicos; a esse sistema deu-se o nome, entre outros, de modelo piramidal. O autor Marcus Oliveira (2009) aponta que tal modelo se constituiu sob as bases políticas do período ditatorial, entre 1964-1985, e que ambicionava utilizar o esporte como ferramenta tanto de poderio simbólico do Brasil perante outras nações, quanto no intuito de abrandar os descontentamentos populares, principalmente aqueles

Pensar a Prática, Goiânia, v. 17, n. 2, p. 443-455, jan./mar. 2014 
oriundos da juventude, contra os desmandos do governo. O modelo piramidal foi estabelecido como o arcabouço do esporte brasileiro e detalhado em 1971 pelo Diagnóstico da Educação Física e Desportos no Brasil.

Esse modelo compreendia que, para se chegar ao topo da pirâmide, caracterizado pelo esporte de alto rendimento, o indivíduo devia passar por várias etapas em que vão se nivelando e afunilando as exigências e o número de integrantes de cada extrato. A massificação esportiva era elemento basilar para congregar os objetivos e necessidades do desenvolvimento esportivo mediante um modelo.

Essa massificação germinaria por intermédio da Educação Física Escolar e/ou desporto escolar, primeiro nível da pirâmide, seguido pela estruturação de equipamentos urbanos básicos para a consolidação desse modelo ${ }^{1}$. O degrau seguinte estava destinado para a promoção das organizações esportivas comunitárias, entre elas os clubes, ligas e federações, que com um grau mais especializado, sistematizado nos limiares entre amadorismo e profissionalismo, configuravam o pequeno passo para o último nível, que seria a elite esportiva (OLIVEIRA, M. A. T., 2009).

Nesse princípio hierárquico, quanto mais alunos tivessem acesso ao esporte escolar, subentendido como a própria Educação Física, mais atletas seriam formados no país. A massificação esportiva iniciada no esporte escolar possibilitaria a identificação de futuros talentos que serviriam às outras etapas do modelo, culminando com a elite esportiva. E a formação de mais atletas serviria de estímulo para o esporte escolar, "o topo da pirâmide deve realimentar a base" (BETTI, 1991, p. 110). Quando se trata do nível da pirâmide que corresponde ao esporte escolar ou Educação Física, historicamente se sabe que:

O Brasil continua não sendo uma potência esportiva mundial e a escola brasileira, que mal cumpre a sua função de transmitir cultura, também não se tornou um "celeiro de atletas", como queria o ideário militar, o qual está redivivo em algumas políticas oficiais, como, por exemplo, alguns programas atuais do Ministério do Esporte voltados à escola. Isso não quer dizer que o esporte não tenha se tornado sinônimo de Educação Física na maioria das escolas brasileiras, empobrecendo a possibilidade de acesso por parte dos alunos a inúmeros outros produtos da cultura afeitos ao corpo e às suas manifestações (OLIVEIRA, M. A. T., 2009, p. 394-395).

No período da década de 1980, a educação brasileira passou por uma grande expansão em virtude do aumento do número de vagas nas escolas. Esse maior acesso à

1

É a partir desse momento que se pode ver a proliferação de parques, ginásios e estádios em todas as cidades como uma ferramenta não só de desenvolvimento do esporte, mas da edificação de um lazer virtuoso e ativo, distante de substâncias ilícitas, da preguiça e do ócio (OLIVEIRA, M. A. T, 2009).

Pensar a Prática, Goiânia, v. 17, n. 2, p. 443-455, jan./mar. 2014 
educação forçou um repensar de todos os atuantes no âmbito escolar quanto à qualidade do ensino ofertado e quais seriam os conhecimentos e requisitos desejáveis na formação dos indivíduos (OLIVEIRA, R. M. M. A., 2009). Esse repensar a prática pedagógica da educação brasileira atingiu pontualmente as práticas educacionais vigentes na Educação Física Escolar e configurou um grande momento de mudança na área.

Esse movimento renovador, segundo Bracht (1999), parte de uma reflexão crítica sobre os domínios pedagógicos e da abordagem tecnicista da aptidão física, analisada e relacionada à reprodução da sociedade capitalista, ao favorecer a injustiça pelos meios competitivos e relegar aos menos habilidosos a oportunidade de se desenvolverem no âmbito da Educação Física Escolar.

Essa crítica mostrou um avanço no intuito de romper com uma prática que em nada estava relacionada com os objetivos pedagógicos de um componente curricular. González e Fensterseifer (2009) admitem ainda que no campo educacional passou-se a questionar o paradigma da aptidão física, que de forma complementar sustentava as práticas pedagógicas da Educação Física Escolar.

Sobre essa configuração, os autores sugerem que a Educação Física Escolar se encontrava em um interstício entre aquilo que classificam como o "não mais" e o "ainda não". Esse "não lugar" da Educação Física no contexto escolar é demarcado pela superação do referencial do "exercitar-se para",2, em contraposição à inconcretude da consolidação de seu status de componente curricular no âmbito escolar.

Com diferentes abordagens e objetivos, vários estudiosos apoiaram distintas possibilidades para a Educação Física perante a crise do paradigma mecanicista. Mas em comum estava o fato de representarem uma inflexão em tudo o que já se tinha vivenciado como objetivos da Educação Física, na busca por deixar de ser uma mera atividade no interior da escola e passar a imprimir o seu verdadeiro caráter como componente curricular, apresentando princípios pedagógicos que a validassem como tal.

No entanto, recorrendo novamente a González e Fensterseifer (2009), é preciso reconhecer que esse projeto renovador não existe enquanto prática hegemônica, implicando a necessidade de investimentos na ressignificação das práticas pedagógicas, com vistas à consolidação do projeto de uma Educação Física comprometida com os propósitos da escola. Ao se partilhar dessa perspectiva, obviamente se acredita que o esporte merece um lugar de destaque dentro de uma proposta curricular articulada a uma Educação Física pautada por um projeto de escola voltada para a leitura de mundo ${ }^{3}$.

O mundo educa para a sua própria reprodução melhorada, mas é a escola que torna possível a consolidação dessa reprodução pela crítica e reflexão que fomentam o

2"Exercitar-se para melhorar a saúde, exercitar-se para formar o caráter, exercitar-se para o desenvolvimento do homem integral" (GONZÁLEZ; FENSTERSEIFER, 2009, p. 12).

3González e Fensterseifer (2009) reconhecem que o fenômeno da natalidade implica a necessidade de tornar acessível às novas gerações os conhecimentos que as possibilitem "sentirem-se em casa no mundo", instituindo esse como o papel sociopolítico fundamental da educação escolar. Ou seja, forjar a desejada "leitura mundo".

Pensar a Prática, Goiânia, v. 17, n. 2, p. 443-455, jan./mar. 2014 445 
estabelecimento das mudanças (GONZÁLEZ, 2006). A Educação Física, portanto, busca: compreender dentro do aspecto educacional a relevância de sua representação na sociedade; proporcionar a leitura de mundo por meio de sua especificidade; fixar-se como uma dimensão da realidade; e propiciar a formação crítica reflexiva e autônoma do aluno por meio de sua dimensão social. Partir da cultura corporal de movimento como conhecimento a ser assimilado pela Educação Física Escolar significa que, pelas diversas manifestações corporais humanas, o indivíduo faz a leitura, interpreta, relaciona e (re)constrói o seu mundo (BETTI; ZULIANI, 2002).

Partindo para as relações entre escola, esporte e Jogos Olímpicos, a primeira conexão que se faz é pela consideração da educação grega na Antiguidade. Esta baseavase em um conceito de educação que visava ao desenvolvimento do ser por completo, sendo essa prática denominada de Paidéia (RUBIO, 2009). É justamente com esse conceito que se inicia o desenvolvimento de atividades esportivas como práticas educacionais escolares, no início do modelo esportivo inglês. Via-se o esporte como importante ferramenta do chamado "desenvolvimento integral", que proporcionava o convívio com o outro, a disciplina às regras, ocupando de forma "salutar" o tempo livre dos escolares (BOURDIEU, 1983).

É sob o conceito da valorização esportiva como ferramenta educativa que Pierre de Coubertin lança a sua iniciativa de restaurar os Jogos Olímpicos na Era Moderna, com base nos propósitos do olimpismo. Esse seria um conjunto de valores pedagógicos e princípios filosóficos do Movimento Olímpico, que tem no esporte o meio principal para o seu desenvolvimento.

No contexto da Educação Física, uma educação sob a égide olímpica pode ser extremamente válida quando considera não apenas os valores olímpicos, mas também estabelece a reflexão da dimensão total do fenômeno esportivo, e não apenas tomando os aspectos positivos, mas identificando os pontos negativos e dando-lhes um trato crítico que favoreça a formação emancipatória do indivíduo perante os desígnios do esporte contemporâneo. É nesse sentido que Vago (1996) propõe a relação de uma tensão permanente entre as práticas hegemônicas do esporte e a escola, para que esta produza uma nova forma de se apropriar do esporte. Então, dessa forma a escola tensionaria:

[...] com os códigos dominantes da sociedade agregados ao esporte (principalmente com a exclusão da prática cultural de esporte a que a ampla maioria dos alunos é submetida e com a ideia de rendimento e performance que predominantemente orientam o seu ensino na escola). (Vago, 1996, p. 12)

Por meio dos Jogos Olímpicos, pode-se buscar a ampliação do que temos hoje como modalidades esportivas dentro da escola, algo para além do tão conhecido "quarteto mágico" (basquete, handebol, vôlei e futsal). É uma oportunidade de se conhecer, com a evidência proporcionada pela maior exposição midiática, outras manifestações culturais do esporte, representadas por novas modalidades esportivas

Pensar a Prática, Goiânia, v. 17, n. 2, p. 443-455, jan./mar. 2014 446 
pouco convencionais no cenário nacional. Também é possível se elencar, com base nos Jogos Olímpicos, temas emergentes em nossa sociedade atual, tais como "proteção ao meio ambiente, o papel da mulher na sociedade, conflitos globais e resolução dos mesmos, racismo e intolerância, promoção do fair play e da ética" (DaCOSTA; GLOMB; GODOY, 2002, p. 346), entre outros; temas esses que também proporcionam eixos para o desenvolvimento de projetos interdisciplinares.

Além disso, a realização de um megaevento esportivo pode representar um momento oportuno para se refletir sobre o multiculturalismo, capaz de estabelecer na escola o reconhecimento de igualdade dos povos, a negação da intolerância e a prática da compreensão (RUBIO, 2009). O multiculturalismo pode também expressar, dentro do âmbito esportivo, o respeito às diversas manifestações corporais, tomando aqui a ideia da diversificação de conteúdos na Educação Física.

Considerando que, "em tempos de megaeventos esportivos, aumenta a circulação social de projetos para a Educação Física escolar e o esporte formal federativo" (BETTI, 2009 , p. 16), fica a dúvida de como os professores poderão lidar com a perspectiva dos Jogos Olímpicos em suas aulas, principalmente por ser o Brasil o próximo país-sede do evento. É importante que se ressalte o papel do professor no direcionamento dessas ações, pois é por sua iniciativa, "e não somente da escola em geral ou das políticas públicas, que reside a possibilidade de uma prática pedagógica ressignificada" (OLIVEIRA, 2010, p. 178).

É desejável e necessário se considerar o protagonismo do professor na consolidação de políticas que apontem para os novos rumos da Educação Física Escolar, sendo exigidas para tanto, a valorização de sua prática pedagógica, a aquisição de conhecimentos e a habilidade, diariamente construídas. No meio acadêmico, principalmente na área da Educação Física, muitas pesquisas estão relacionadas ao que os professores devem fazer e como fazê-lo. Poucas se destinam a ouvir o professor em seu contexto e prática, e em como, pelas relações diárias com os alunos, eles estabelecem suas teias de significado (OLIVEIRA, 2010).

Tardif (2008) considera que a prática docente integra diferentes saberes, com os quais os professores mantêm diferentes diálogos. Mesmo tendo em conta a importância da formação inicial na vida profissional dos professores, grande parte da sua formação acontece na prática pedagógica na escola, para além do conhecimento acadêmico, objetivando no ensinar as suas concepções de mundo. Nesse sentido, o presente estudo teve o objetivo de investigar e analisar quais as perspectivas de professores de Educação Física em relação às suas práticas pedagógicas com a realização dos Jogos Olímpicos de 2016 no Brasil.

\section{Processo Metodológico}

Para a realização desta pesquisa, foi utilizada a abordagem qualitativa. A matriz metodológica desenvolvida respaldou-se no referencial da pesquisa descritivoexploratória, que compreende observar, registrar, analisar, descrever e correlacionar fatos 
para que se possa explanar sobre determinado fenômeno, familiarizando-se e obtendo novas ideias em relação ao objeto de estudo (MATTOS; ROSSETTO JÚNIOR; BLECHER, 2004).

Para a seleção dos participantes, usou-se o critério de amostragem aleatória por área (COOPER; SCHINDLER, 2003), que consiste em organizar a população em áreas geográficas e selecionar aleatoriamente, em cada uma, sujeitos para a pesquisa. Dessa maneira, foram escolhidos aleatoriamente seis professores de Educação Física do município de São Carlos/SP, que representavam cada uma das regiões da cidade (norte, sul, leste, oeste, região central e zona rural), atuantes na rede estadual do $9^{\circ}$ ano do Ensino Fundamental.

A cada participante foi designada uma sigla - P1, P2, P3, P4, P5 e P6 - com o objetivo de manter o sigilo de identidade, respeitando assim os aspectos éticos devidos. Utilizou-se a entrevista semiestruturada para coleta de dados, e para a interpretação do material foram definidas categorias de análise, a posteriori, que segundo Gomes (2004) consistem em conceitos-chaves que abrangem elementos ou aspectos comuns, no intuito de agruparem ideias e expressões que possam servir de base para o estudo.

\section{Resultados}

As opiniões dos professores ${ }^{4}$ quanto às relações pedagógicas entre Jogos Olímpicos e Educação Física Escolar foram organizadas em duas categorias identificadas com base na análise das entrevistas, delimitando-se temas emergentes em cada entrevista transcrita. Em seguida, foram identificadas as categorias que melhor abarcavam os temas surgidos sem que perdessem a riqueza de seu significado. Pela compreensão do que os professores declararam sobre a sua prática pedagógica e as relações com os Jogos Olímpicos, identificaram-se duas categorias que corresponderam às suas opiniões: 1) Impossibilidades e 2) Possibilidades.

\section{Impossibilidades}

Foram identificadas como impossibilidades aquilo que os professores definiram como barreiras e obstáculos impeditivos diante de uma prática pedagógica que relacione Jogos Olímpicos e suas aulas de Educação Física Escolar. Aqui também se considerou o que os professores julgaram ser problemático com a própria realização dos Jogos Olímpicos no Brasil.

Quando se pensa em Jogos Olímpicos, o que primeiro se identifica é o grande evento esportivo, a grande estrutura e também os atletas. Voltando ao modelo piramidal (BETTI, 1991), ao relacionar Jogos Olímpicos e Educação Física Escolar, grande parte do senso comum vê a escola como um meio de promover os atletas que representarão o

4Os resultados encontrados contêm a transcrição das entrevistas mantendo o discurso original dos entrevistados, sem correções.

Pensar a Prática, Goiânia, v. 17, n. 2, p. 443-455, jan./mar. 2014 
país. É dessa forma que alguns professores, ao pensarem no diálogo Jogos Olímpicos e Educação Física Escolar, se referiram, nesse caso, como uma impossibilidade de diálogo, uma vez que os objetivos da Educação Física não mais correspondem a alimentar o topo da pirâmide:

Talvez, próximo, mais próximo, interfere, mas agora, no momento, eu acho que quem tinha que ter tirado de algum lugar pra um treino mais especifico já fez (P3).

Eu não acredito, eu não acredito que vai ter uma interferência, infelizmente a educação não é voltada para a formação de atleta, esse tipo de coisa. A situação, infelizmente, você prepara o aluno pra fazer uma atividade física (P6).

Pode-se perceber aqui que os professores limitam o diálogo das duas instâncias, Educação Física e Jogos Olímpicos, somente por essa implicação. A visão de que a Educação Física não é mais produtora de talentos esportivos é lamentada pelo professor e coloca em questão até que ponto o modelo piramidal perdura no ideário de quem atua na área, mostrando o entendimento do professor perante o que ele acredita que deveria ser o papel da Educação Física na escola. Esse pensamento subordina a Educação Física às premissas do esporte enquanto prática de rendimento, pois se buscaria o desenvolvimento esportivo pela escola, deturpando os objetivos educacionais.

Cabe destacar que o discurso dos professores lamentando sobre o fato de não se atrelar a Educação Física Escolar à formação de atletas pode ser interpretado como tributário daquilo que González e Fensterseifer (2009) chamaram do "não mais". Tais discursos evocam uma representação ancorada no exercitar-se para o esporte de alto rendimento, que já devia estar superado na cena da Educação Física Escolar, mas ainda concorre com as finalidades vigentes, sobretudo em virtude da condição do "ainda não" manifestada pelos autores. Esse "não lugar" pode ser identificado pelo estabelecimento da condição de componente curricular à Educação Física, do ponto de vista legal e do discurso acadêmico, em contraposição à inconcretude dessa condição na prática pedagógica.

Quando perguntados sobre como o evento poderia ou não interferir em suas realidades, alguns professores mostraram a relação temporal dos efeitos que o evento poderá causar na Educação Física Escolar, como algo que tende a não ter continuidade depois de finalizado o evento:

E a molecada vai começar a assistir; porém, a hora que acabar o evento, vai ser como se fosse um tsunami, uma nuvem, e depois a gente volta ao normal. Pela escassez do projeto. (P4)

Eu acho que no momento vai dar aquela mexida nos alunos, eu acredito nisso. Mas eu acho que depois vai muito do interesse dos alunos em

Pensar a Prática, Goiânia, v. 17, n. 2, p. 443-455, jan./mar. 2014 
buscar aquilo, e eu acho que não sei se a gente vai ter, porque o próprio Brasil, não só a Educação Física, se o próprio Brasil vai dar uma sequência disso. (P2)

Os professores definem que o envolvimento dos alunos vai acontecer, mas será passageiro, por falta de um engajamento em nível governamental. Nesse sentido, vê-se que os investimentos não contemplam a consolidação de um legado educativo, isso é explicitado até mesmo pela falta de discussão e reflexão sobre o evento pelos profissionais da escola, e por ainda não ter sido encaminhado nenhum planejamento concreto quanto a isso. Para os professores, no momento em que o evento estiver acontecendo haverá um incentivo e envolvimento dos alunos, haverá um destaque para a área, mas, assim que o os jogos acabarem, essa dinâmica também cessará.

Cabe destacar no discurso do professor P2 a percepção de responsabilização do aluno e do governo ("o próprio Brasil") pela ampliação do legado da cultura esportiva. Tal perspectiva tende a negligenciar o papel protagonista do professor enquanto agente da potencialização de políticas voltadas para a ampliação da cultura esportiva.

Com essa análise, não se pretende menosprezar a condição de protagonista também do aluno nesse processo, muito menos isentar de responsabilidade as agências governamentais que precisam ser cobradas nesse sentido. Contudo, não se pode deixar de apontar a relativa omissão dos próprios professores ao deixarem de indicar as possibilidades que poderiam ser exploradas por eles na condição de agentes capitais para a efetivação de qualquer tipo de política educacional, por estarem na "ponta de ação" dessas políticas.

\section{Possibilidades}

Nessa categoria foram identificados nas falas dos professores pontos que eles consideraram convergir entre os Jogos Olímpicos e suas práticas pedagógicas, e encararam como sendo de possível diálogo com o grande evento esportivo e o cotidiano de suas aulas de Educação Física.

Quando perguntados sobre como eles poderiam se utilizar do momento oportuno dos Jogos Olímpicos em suas práticas pedagógicas, os professores apontaram o que seria potencialmente factível:

Aproveitar isso e de repente desenvolver um trabalho interdisciplinar, né? Envolver aí outras áreas, conhecer os países que estão disputando, saber o quê que tem, por que esse evento é tão grande, saber o quê que envolve, o quê que demanda a realização de um evento desse. (P2)

Eu acho que a Olimpíada dá um vasto campo pro aluno poder ver, poder assistir alguma coisa e ficar por dentro do esporte olímpico. Ter um aproveitamento com base no processo histórico, né, de pesquisar de onde veio, de onde começou, como que eram as modalidades, que veio

Pensar a Prática, Goiânia, v. 17, n. 2, p. 443-455, jan./mar. 2014 
lá da Grécia. Eu acho que vai ser muito oportuno esses Jogos Olímpicos aqui no Brasil, pra Educação Física Escolar. (P1)

Então você usa os bons exemplos da competição, a questão das disputas, porque que tem países que tem aquela cultura enraizada em determinado esporte, porque que nós não poderíamos estar desenvolvendo situações semelhantes, enfim. Tento despertar nele a curiosidade por outros esportes, inclusive que não são praticados no momento. (P6)

Os professores colocam a prática pedagógica interdisciplinar e o trato histórico cultural das modalidades como possibilidades de diálogo entre a Educação Física Escolar e os Jogos Olímpicos. O que foi pontuado pelos professores faz eco com o que DaCosta, Glomb e Godoy (2002) mostram como sendo as potencialidades dos Jogos Olímpicos em intercâmbio com o âmbito educacional, principalmente a abordagem do evento como um fenômeno multifacetado e interdisciplinar. Esses pontos também estão de acordo com a possibilidade multicultural tratada por Rubio (2009).

Nos fragmentos das falas anteriores e na que se segue, destaca-se a questão da mídia como ponto interlocutor entre os Jogos Olímpicos e a prática pedagógica:

Porque é divulgado, eu até já trabalhei numa escola nos Jogos Olímpicos passados que a gente montava TV, uma oportunidade pra gente explicar pras crianças como é que funcionava. E eles acabam se envolvendo mais, se interessam mais. Às vezes ele não tem nem o conhecimento de que existe aquele esporte, então, a partir do momento que eles começam ver e assistir, principalmente nas Olimpíadas, eles têm mais interesse, vão atrás.. [...] os professores acabam se envolvendo, sim, então a gente fazia trabalhinho, fazia pesquisa, fazia o Dia das Olimpíadas na escola. (P5)

Nesse contexto, cabe salientar que, "por ocasião de Jogos Olímpicos é que se ouve com alguma frequência referências à Educação Física escolar, principalmente na mídia" (BETTI, 2009, p. 19-20). É interessante aproveitar essa ocasião justamente para o despertar dos alunos para as diferentes práticas, mas também para conduzi-los ao entendimento de todas as instâncias do fenômeno esportivo. Seria um momento de aproveitar-se do espetáculo televisivo e inserir novas maneiras de pensar as práticas pedagógicas, para além da exclusividade do "quarteto mágico".

Muitas das informações veiculadas pela mídia "possuem apenas a forma do espetáculo e do entretenimento, distante de preocupações educativas formais" (BETTI, 2001, p. 125). Assim, o professor deve colocar-se como mediador do que é exposto pela mídia e o conhecimento pedagógico a ser trabalhado em aula, para que possa refletir com os alunos sobre como se colocar diante do fenômeno midiático.

Pensar a Prática, Goiânia, v. 17, n. 2, p. 443-455, jan./mar. 2014 
De certa maneira, os professores caminham para um entendimento positivo de realizar a mediação entre Jogos Olímpicos e prática pedagógica. Porém, é necessário entender que o momento é relevante também para valorizar as vivências das práticas corporais veiculadas pelo advento dos Jogos Olímpicos, compreendendo a riqueza motora das diferentes manifestações esportivas.

A escola pode não apresentar uma composição adequada de materiais, equipamentos e infraestrutura, mas é possível encaminhar as aulas por meio de adaptações, pedagogizando inclusive o fato de não se ter os requisitos oficiais para a implementação das modalidades olímpicas. Além disso, considera-se oportuno chamar a atenção para a necessidade de se fomentar políticas públicas para que os professores possam organizar e sistematizar as propostas apresentadas em seus discursos, tendo em vista que elas encontram-se desprovidas de referenciais teórico-práticos que possibilitem a superação do senso comum ou mesmo das informações descontextualizadas e acríticas, disponíveis a qualquer pessoa nos meios de comunicação e que tendem a se multiplicar exponencialmente em tempos de megaeventos.

\section{Considerações Finais}

A proximidade da realização dos Jogos Olímpicos no país, aliada às constantes mudanças da Educação Física Escolar mediante as influências e demandas da sociedade brasileira, configuraram pressupostos inquietantes. Assim, o intuito desta pesquisa foi investigar e analisar quais as implicações dos Jogos Olímpicos de 2016 à realidade da nossa área escolar, com base na opinião dos professores atuantes no ensino da Educação Física de São Carlos/SP.

Vários foram os apontamentos dos professores pesquisados. Ao pensarem na relação Jogos Olímpicos e Educação Física Escolar, alguns logo associaram a formação de atletas e a identificação de talentos esportivos, o que confirma a perspectiva da pirâmide esportiva. Mas outros professores também apontaram novas possibilidades de abordar os Jogos Olímpicos em suas aulas, tais como o trabalho interdisciplinar com outras áreas de conhecimento e o trato histórico-cultural das modalidades.

Apesar de acreditarem que será um momento de despertar para novas modalidades por parte dos alunos, em vista da exposição esportiva pela mídia, poucos foram os professores que pensaram nisso como uma oportunidade de renovar a prática esportiva dentro das aulas, apresentando aos alunos vivências práticas de modalidades diferentes das que acontecem normalmente. A falta de planejamento é uma das questões apontadas pelos professores, pois eles acreditam que o possível legado educativo será passageiro pela falta de projeto e antecipação de estratégias que favoreçam a consolidação de implicações positivas.

Com base nessa problemática, torna-se latente uma abertura para que professores pensem suas práticas por uma visão mais ampla do que é ser país-sede de uma Olimpíada. Que pensem que será um momento oportuno para reavivar a prática do esporte dentro da escola, mas não pela reedição de uma abordagem tradicional

Pensar a Prática, Goiânia, v. 17, n. 2, p. 443-455, jan./mar. 2014 452 
esportivista, e sim para pensar o esporte como um fenômeno cultural amplo, que proporciona várias facetas para ser abordado pedagogicamente na escola, envolvendo a relação completa do conteúdo.

Que os professores pensem que o esporte tem uma amplitude prática que não pode, e nem deve, ser reduzida ao ensino de determinadas modalidades, tampouco se restringir às repetições de movimentos técnicos, ou somente vivências, mas que deve compreender toda a sua riqueza histórica, ideológica e crítica. Que, com isso, se possam enxergar as inúmeras possibilidades de se fazer uma Educação Física de qualidade, com a utilização efetiva de todos os eixos que comportam esse componente curricular.

Com esses pressupostos, considera-se de suma importância que os professores não se omitam do seu papel de protagonistas para a efetivação de projetos voltados para a tematização dos Jogos Olímpicos, sem perder de vista a necessidade de participação do poder público. Este deve fomentar políticas que propiciem um equilíbrio entre a valorização desse protagonismo docente, articulado ao arcabouço conceitual, forjando uma proposta que reflita o diálogo entre o contexto local e os Jogos Olímpicos pelo ponto de vista da formação do aluno praticante, espectador e consumidor do megaevento esportivo.

\title{
PEDAGOGICAL RELATIONS BETWEEN PHYSICAL EDUCATION AND OLYMPIC GAMES
}

\begin{abstract}
The present study aimed to investigate and analyze what education teachers Físicaas perspectives in relation to their pedagogical practices, with the Olympic Games 2016 in Brazil. For this study a qualitative approach was used semi-structured interviews with six teachers of physical education, active in the state, in São Carlos/SP. The analysis of categorical data was used and it was found that teachers indicate dialog possible with the Olympic Games in their classes, despite having, at times, limited vision sports content. It is considered the discussion of critical dialogue of the Olympic Games in school very important, and teachers protagonists of this process.

Keywords: School Physical Education. Olympic Games. Pedagogical Practice.

\section{RELACIONES PEDAGÓGICAS ENTRE LA EDUCACION FÍSICA Y LOS JUEGOS OLÍMPICOS}

\section{Resumen}

El presente estudio tuvo como objetivo investigar y analizar las perspectivas de los profesores de educación física en relación con sus prácticas pedagógicas, con los Juegos Olímpicos de 2016 en Brasil. Se utilizó un enfoque cualitativo a través de entrevistas semi-estructuradas con seis profesores de Educación Física, trabajando en el estado en el municipio de São Carlos/SP. Se utilizo la análises por categorias y se dio cuenta de que los maestros señalaron posibilidades de diálogo de los Juegos Olímpicos en sus clases, a pesar de tener, a veces, la visión limitada sobre el contenido de los deportes. Se considera que es importante discutir la tematización crítica de los 
Juegos Olímpicos en la escuela, y creemos que los profesores son los protagonistas de este proceso.

Palabras-claves: Educación Física Escolar. Juegos Olímpicos. Práctica Pegagógica.

\section{Referências}

BETTI, M. Educação física e sociedade. São Paulo: Editora Movimento, 184p, 1991.

. Mídias: aliadas ou inimigas da educação física escolar? Motriz, Rio Claro, v. 7, n. 2, p. 125-129, dez. 2001.

- Copa do Mundo e jogos olímpicos: inversionalidade e transversalidades na cultura esportiva e na educação física escolar. Revista Motrivivência, Florianópolis, ano XXI, n. 32/33, p. 16-27, jun./dez. 2009.

BETTI, M.; ZULIANI, L. R. Educação física escolar: uma proposta de diretrizes pedagógicas. Revista Mackenzie de Educação Física e Esporte, São Paulo, v. 1, n. 1, p. 73-81, jan./dez. 2002.

BOURDIEU, P. Como é possível ser esportivo? In: Questões de sociologia. Rio de Janeiro: Marco Zero, p. 136-153, 1983.

BRACTH, V. A constituição das teorias pedagógicas da educação física. Cadernos CEDES, Campinas, v. 19, n. 48, p. 69-88, ago. 1999.

COOPER, D.; SCHINDLER, P. Métodos de pesquisa em administração. 7. ed. Porto Alegre: Bookman, 640p, 2003.

DaCOSTA, L. P.; GLOMB, M. P.; GODOY, L. Educação olímpica no ensino fundamental. In: DaCOSTA, L. P.; TURINI, M. (Editores). Estudos Olímpicos. Rio de Janeiro: Editora Gama Filho, p. 343-354, 2002.

GOMES, R. A análise de dados em pesquisa qualitativa. In: MINAYO, M. C. S. (Org.). Pesquisa social: teoria, método e criatividade. 23. ed. Petrópolis: Vozes, p. 67-80, 2004.

GONZÁLEZ, F. J. Projeto curricular e educação física: o esporte como conteúdo escolar. In: REZER, R. (Org.). O fenômeno esportivo ensaios crítico-reflexivos. Chapecó: Argos, p. 69-109, 2006. 
GONZÁLEZ, F. J.; FENSTERSEIFER, P. E. Entre o "não mais" e o "ainda não": pensando saídas do não lugar da EF escolar I. Cadernos de Formação RBCE, Florianópolis, v. 1, n. 1, p. 9-24, set. 2009.

MATTOS, M. G.; ROSSETTO JÚNIOR, A. J.; BLECHER, S. Teoria e prática da metodologia da pesquisa em Educação Física. São Paulo: Phorte, 162p, 2004.

OLIVEIRA, M. A. T. O esporte brasileiro em tempos de exceção: sob a égide da ditadura (1964-1985). In: PRIORE, M. D.; MELO, V. A. (Orgs.). História do esporte no Brasil: do império aos dias atuais. São Paulo: Editora UNESP, p. 387-416, 2009.

OLIVEIRA, R. C. Na "periferia" da quadra: educação física, cultura e sociabilidade na escola. 2010. 201f. Tese (Doutorado em Educação Física) - Programa de Pós-Graduação em Educação Física da Universidade Estadual de Campinas, Campinas, 2010.

OLIVEIRA, R. M. M. A. Ensino e aprendizagem escolar: algumas origens das ideias educacionais. São Carlos: EDUFSCar, 80p, 2009.

RUBIO, K. O legado educativo dos megaeventos esportivos. Revista Motrivivência, Florianópolis, v. 2, n. 32/33, p. 71-88, jun./dez. 2009.

TARDIF, M. Saberes docentes e a formação profissional. 9. ed. Petrópolis: Vozes, 325p, 2008.

VAGO, T. M. O "esporte na escola" e o "esporte da escola": da negação radical para uma relação de tensão permanente. Revista Movimento, Porto Alegre, v. 3, n. 5, p. 4-17, 1996.

Recebido em: 21/06/2013

Revisado em: 22/10/2013

Aprovado em: 26/11/2013

Endereço para correspondência:

vivi9paes@ hotmail.com

Viviane Ribeiro Paes

Universidade Federal de São Carlos.

rodovia washington Luis, 235

13565-905 - Sao Carlos, SP - Brasil

Pensar a Prática, Goiânia, v. 17, n. 2, p. 443-455, jan./mar. 2014 